International Journal of Translational

Medical Research and Public Health (2018),Volume 2, Issue 2, 25-27

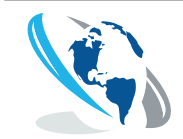

IJTMRPH
INTERNATIONAL JOURNAL OF TRANSLATIONAL

Medical Research and Public Health ISSN: 2576-9499 (Online)

ISSN: 2576-9502 (Print)

Available online at www.ijtmrph.org DOI: 10.21 106/ijtmrph.5।

\title{
SHORT COMMUNICATION | MEDICAL EDUCATION \\ Motivators and Incentives of Pediatric Medical Educators in an Academic Hospital Setting in the United States
}

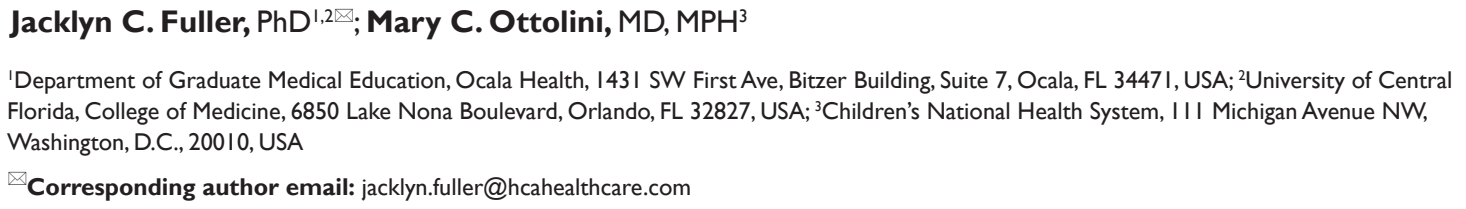

Corresponding author email: jacklyn.fuller@hcahealthcare.com

\section{ABSTRACT}

Graduate medical education (GME) has undergone a phenomenal transformation aimed at aligning medical education and the learning environment with educational outcomes and quality patient care. The Accreditation Council for Graduate Medical Education (ACGME) has challenged faculty to adapt to novel teaching methodologies. However, there are limited studies about motivational factors that impact pediatric graduate medical educators. This article brings an insight to these motivators from the perspectives of teaching and clinical pediatric educators at an academic teaching hospital.

Keywords: Graduate Medical Education - GME - Pediatrics • Medical Educators - Clinical Teachers • Motivators • Incentives $•$ Hospital • Faculty

Copyright (C) 2018 Fuller et al. Published by Global Health and Education Projects, Inc. This is an open-access article distributed under the terms of the Creative Commons Attribution License CC BY 4.0. 


\section{Introduction}

Graduate medical education (GME) has changed remarkably, as it now seeks to align the medical curriculum and learning environment with specific academic outcomes and the provision of quality patient care. The Accreditation Council for Graduate Medical Education (ACGME) has challenged faculty to adapt to novel teaching methodologies to accommodate the different learning modalities of the next generation of physicians.' The ACGME Next Accreditation System (NAS), is designed to emphasize quality, educational and clinical accountability, and advance medical education (Table I). The goal of these efforts is to improve physician educational outcomes and performance through a process of continuous evaluation of six competencies during training., 3

However, variation among clinical teachers is one of the barriers against standardization. ${ }^{4}$ Like other medical educators, pediatric faculty educators are faced with demands for increased clinical productivity, leaving less time to commit to professional development and scholarship. On the other hand, scholarly activities may be one of the most effective ways to learn and practice evidence based medicine (EBM). ${ }^{5}$

Previous studies have identified intrinsic issues such as altruism, intellectual satisfaction, personal skills and truth seeking, as the main factors influencing motivation to teach medical students. ${ }^{6}$ However, extrinsic factors such as rewards or recognition were also motivators. ${ }^{7}$ The key barriers keeping clinicians from teaching were decreased productivity, lack of compensation, increased length of the working day, concerns about patients, ethics, and lack of confidence about their personal skill.' Bartle and Thistlethwaite identified six key themes in motivation for career choice and wanting to provide better education to medical students: personal goals, expectations and the need for self-direction, the influence of role models, defining one's identity, support networks and the need for research as a potential barrier to pursuing an educational career. ${ }^{8}$
Table I:The pediatrics milestone project, a result of the next accreditation system ${ }^{(3)}$

\begin{tabular}{lc}
\hline $\begin{array}{l}\text { ACGME } \\
\text { competencies }\end{array}$ & $\begin{array}{c}\text { Total number of } \\
\text { sub-competencies }\end{array}$ \\
\hline Patient care & 5 \\
\hline Medical knowledge & $\mathrm{I}$ \\
\hline Systems-based practice & 3 \\
\hline Practice-based learning & 4 \\
\hline Professionalism & 5 \\
\hline Interpersonal \& & 2 \\
communication skills & 20 \\
\hline Total & \\
\hline
\end{tabular}

\section{Methods}

In 20I5, a study that consisted of semi-structured face-to-face interviews and focus groups was conducted with 10 board certified medical educators, including faculty from eight disciplines who have clinical and educational responsibilities, in pediatrics. The responses of the educators were audio recorded, which were then analyzed to establish themes, patterns, and trends for motivators and incentives.

\section{Results}

The findings from the study showed that emergent action is needed for the following themes (Table 2).

Table 2: Emergent themes from interviews with pediatrics faculty

\begin{tabular}{l}
\hline | Protected time for scholarly work development \\
\hline | Need for resources: \\
\hline o Mentorship from senior staff \\
\hline o Support with manuscript preparation \\
\hline o Research design, methodology, statistics \\
\hline | Recognition and reward \\
\hline | Collaboration across disciplines \\
\hline | Culture of prioritizing clinical revenue over scholarly \\
development \\
\hline | Focus of previous medical program \\
\hline I Intrinsic love for teaching \\
\hline | Self-motivation
\end{tabular}




\section{Conclusions and Implications for Translation}

Overall, pediatric faculty educators strived for increased scholarly and educational throughput, but perceive success only if appropriate support systems were in place. The following strategies were recommended to help achieve this goal:

- Required faculty development in time management/efficiency.

- Establishment of a formalized mentorship program.

Limitations to this study included a small sample size, limited range of disciplines, and the involvement of a single institution.

\section{Compliance with Ethical Standards}

Conflicts of Interests: The authors declare that they have no conflict of interest. Financial Disclosure: This research did not receive any specific grant from funding agencies in the public, commercial, or not-for-profit sectors.

Acknowledgments: The authors would like to thank Dr. Hale Toklu from the Department of Graduate Medical Education (University of Central Florida/HCA GME Consortium) for her contribution. Ethical Approval: This study was approved by an approved Institutional Review Board. Disclaimer: None. Funding/Support: There was no funding for this study.

\section{Key Messages}

- The Accreditation Council for Graduate Medical Education (ACGME) Next Accreditation System (NAS) is designed to emphasize quality, educational and clinical accountability, and advanced medical education.

- An appropriate support system is recommended for pediatric faculty educators such as faculty development and mentorship program.

\section{References}

I. Desy JR, Reed DA, Wolanskyj AP. Milestones and millennials: a perfect pairing-competency-based medical education and the learning preferences of generation Y. Mayo Clin Proc. 20 17;92(2):243-250. doi: 10.1016/j.mayocp.2016.10.02

2. Feist TB, Campbell JL, LaBare JA, Gilbert DL. Challenges in implementation of the new accreditation system.J Child Neurol. 2017;32(4):397402. doi: |0. I |77/08830738|668524|

3. Accreditation Council for Graduate Medical Education and American Board of Pediatrics. The Pediatrics Subspecialty Milestone Project. ACGME and ABP;20I5.

4. Diner BM, Carpenter CR, O'ConnellT, et al. Graduate medical education and knowledge translation: role models, information pipelines, and practice change thresholds. Acad Emerg Med. 2007; I4(II):I008-14. doi: 10.1 197/j.aem.2007.07.003

5. Regan L, Stahmer S, Nyce A, et al. Scholarly tracks in emergency medicine. Acad Emerg Med. 2010;17 Suppl 2:S87-94. doi: 10.1III/j.1553$2712.2010 .00890 . x$.

6. Dahlstrom J, Dorai-Raj A, McGill D, Owen C, Tymms $\mathrm{K}$, Watson DA. What motivates senior clinicians to teach medical students? BMC Med Educ. 2005;5:27. doi: 10.1 186//472-6920-5-27

7. McCullough B, Marton GE, Ramnanan CJ. How can clinician-educator training programs be optimized to match clinician motivations and concerns? Adv Med Educ Pract. 2015;6:45-54. doi: 10.2I47/AMEP. S70139

8. Bartle E, Thistlethwaite J. Becoming a medical educator: motivation, socialisation and navigation. BMC Med Educ. 2014;14:110. doi: 10.1186/14726920-14-II0. 